\title{
Prospection inventaire en Saintonge
}

\section{Thierry Le Roux et Yves Olivet}

Édition électronique
URL : http://journals.openedition.org/adlfi/3063

ISSN : 2114-0502

Éditeur

Ministère de la culture

Référence électronique

Thierry Le Roux et Yves Olivet, « Prospection inventaire en Saintonge », ADLFI. Archéologie de la France - Informations [En ligne], Poitou-Charentes, mis en ligne le 01 mars 2009, consulté le 03 mai 2019.

URL : http://journals.openedition.org/adlfi/3063

Ce document a été généré automatiquement le 3 mai 2019.

(c) Ministère de la Culture et de la Communication, CNRS 


\title{
Prospection inventaire en Saintonge
}

\author{
Thierry Le Roux et Yves Olivet
}

Identifiant de l'opération archéologique : 204723

Date de l'opération : 2009 (PI)

\section{Prospection de surface}

En 2008, la prospection de la vallée du Bruant en amont de la Roche Courbon avait essentiellement permis d'évaluer un potentiel archéologique lié à l'existence de multiples grottes, certaines récemment explorées.

Cette année nos efforts se sont portés sur les plateaux situés de part et d'autre du ruisseau. De nouveaux sites préhistoriques ont été répertoriés, approfondissant notre connaissance de ces secteurs. Les recherches se poursuivront en 2010 avec un projet de carte archéologique de la commune.

Le résultat de cette année révèle dix-huit sites dont les fiches de déclaration ont été établies. Dans le détail, on note treize sites néolithiques (dont six du Néolithique final confirmés et trois se situant dans la transition entre Néolithique récent et final), un site paléolithique supérieur avec un débitage laminaire très pur (malheureusement aucun outil n'a été trouvé), quatre sites moustériens dont quelques pièces évoquent le type Quina déjà localement attesté par André Debénath à l'Abri Supérieurde la Vauzelle

Trois sites du Néolithique final permettent d'observer des armatures bifaciales sans pédoncule ainsi que des armatures en amande. On retrouve d'ailleurs ces pointes en quantité non négligeable dans les collections du musée de Préhistoire au Château de la Roche Courbon avec pour provenance la seule mention « secteur de Saint-Porchaire ». On connaît ces armatures à la charnière du Néolithique récent et final, sorte de transition entre la culture des pointes tranchantes et perforantes. L'abondance de ce mode de façonnage sur cette zone interroge sur la longévité de cette culture, même si un simple ramassage de surface limite notre analyse. 


\section{2 - Grotte du Triangle}

En 2008, suite à la découverte d'une plaquette calcaire ornée de triangles cloisonnés, nous avions entrepris de passer en revue tous les rochers amassés dans la grotte ainsi que dans sa galerie et son boyau dits « des Escargots ». L'extraction d'environ $2 \mathrm{~m}^{3}$ de pierres et de déchets divers (tuiles, chaussures, etc.) n'a hélas pas livré d'autre bloc gravé mais a permis de mettre en évidence, environ $0,50 \mathrm{~m}$ au-dessus des couches en place, un matériel archéologique démantelé et éparpillé par le passage des fouisseurs dans un contexte sensiblement remanié par l'homme. Ce matériel a été étudié en 2009 , avec l'aimable concours de Jean-François Tournepiche pour la détermination des ossements.

- Lithique

Au total cinquante-six silex ont été collectés. Il s'agit principalement d'éclats, de nucléus et d'un grattoir. Quarante et un font référence au Paléolithique moyen et quatorze au Paléolithique supérieur. Le Moustérien, majoritairement à débitage Levallois, correspond à $74 \%$ de la masse contre $25 \%$ pour le Paléolithique supérieur.

- Céramique

Quelques échantillons de céramique ont été ramassés tant en surface que dans la cavité. La poterie n'est pas homogène et irait du Néolithique à l'époque médiévale.

- Ossements humains

Un métacarpe et une vertèbre ont été recueillis dans la galerie dite « des escargots » : il est probable que nous soyons en présence d'une sépulture mais les ossements n'ont pas la même couleur et le même état de conservation que ceux de la faune attribuée au Paléolithique.

- Faune

Trois cent neuf fragments d'ossements dont de nombreuses dents ont été récoltés, la plupart provenant de morceaux de brèche mêlés aux éboulis ou au remplissage terreux. Le cheval prédomine avec quarante-trois éléments ( $22 \%$ de la masse osseuse). Equus hydruntinusreprésente $4,4 \%$ de la masse avec vingt ossements. On compte quatorze os de Bovinés (10 \% de la masse). Les autres espèces comprennent une dent de cerf, deux dents de renne, trois dents d'hyène, une dent de lion, quatre dents et un os d'ours des cavernes, une dent d'ours brun. Il reste $1,8 \mathrm{~kg}$ de portions de brèche comportant des ossements divers à identifier.

\section{3 - Cavernes saintongeaises}

Plusieurs grottes saintongeaises ont fait l'objet de réexamens minutieux et dévoilé des dispositifs d'aménagement en cours d'interprétation. Elles figurent dans la base de données spéléologiques Charente « Inférieure », rassemblant plus de trois mille fichiers.

Un autre temps fort et un énorme travail bénévole résidait dans la réalisation d'une salle d'«Initiation à la préhistoire» au musée du Château de la Roche Courbon. Cette opération, qui sera achevée fin 2009, a été rendue possible grâce aux subventions accordées, à l'Association AMI-COUR, par le conseil général et la Caisse régionale du Crédit agricole. 
Une seconde tranche de rénovation concernera la deuxième salle du musée qui sera consacrée à la "Préhistoire départementale». On en découvrira le projet et le contenu partiel sur le site Internet « Cavernes en Saintonge » (pages « Cavernes \& Préhistoire » et " musée LRC » régulièrement actualisées et enrichies de nouveaux documents).

OLIVET Yves et LE ROUX Thierry

INDEX

peuple Moustérien type Quina

operation Prospection inventaire (PI)

Index géographique : Poitou-Charentes, Charente-Maritime (17)

Thèmes : armature, biface, boviné, carte archéologique, céramique, cerf, cheval, débitage, dent, éclat, faune, galerie, grattoir, grotte, hyène, industrie lithique, lion, nucleus, ossement animal, ossement humain, ours, plaquette gravée, plateau relief, renne, serveur informatique, technique Levallois

Index chronologique : Moyen Âge*, Néolithique, Paléolithique supérieur, Préhistoire

\section{AUTEURS}

YVES OLIVET

BEN 